\title{
UNA APROXIMACIÓN A LA VIDA Y OBRA DE SEBASTIÁN VIDAL, MAESTRO MAYOR DE LA CATEDRAL DE CÓRDOBA EN EL SIGLO XVII
}

\section{AN APPROACH TO THE LIFE AND WORK OF SEBASTIÁN VIDAL, MASTER BUILDER OF THE CATHEDRAL OF CORDOBA IN THE 17TH CENTURY}

\author{
Jesús SuÁrez Arévalo \\ Universidad Nacional de Educación a Distancia. España \\ ORCID: 0000-0002-7990-2917 \\ jesus.suarez68@gmail.com
}

\begin{abstract}
Sebastián Vidal fue uno de los maestros mayores de la catedral de Córdoba durante el siglo XVII, cargo que simultaneó con el de maestro mayor de la ciudad. Pese a la relevancia de la posición que ocupó, se trata de un personaje relativamente desconocido del que hasta ahora solo se ha estudiado su faceta de retablista. En este artículo, partiendo de fuentes documentales, pretendemos establecer un catálogo actualizado de sus trabajos y recoger nuevos datos sobre su biografía, su estatus y sus relaciones sociales.

Palabras clave: arquitectura; maestros mayores; Sebastián Vidal; Córdoba; Barroco.
\end{abstract}

Sebastián Vidal was one of the main Master builders of the Cathedral of Cordoba during the seventeenth century. This position was combined with that of Master builder of the city. Despite of this, he is a relatively unknown architect and only his role as an altarpiece builder has been studied so far. We intend to establish an updated catalog of his works and collect new data on his biography, his status and his social relationships according to archive sources.

Keywords: architecture; master builders; Sebastian Vidal; Cordoba; Baroque.

\section{INTRODUCCIÓN}

El estudio de los maestros mayores que tuvo la catedral de Córdoba durante el siglo XVII está aún por hacer, pese a que el cabildo catedralicio fue el principal 
promotor artístico de la ciudad del momento. Gracias a las cuentas de fábrica ${ }^{1}$, hemos podido reconstruir en gran parte la nómina de maestros que ocuparon el puesto tras la muerte de Juan de Ochoa en 1606. Se trata de Blas de Masavel, Pedro Freila de Guevara, Sebastián Vidal, Domingo de Mendigoitia, Bartolomé Muñoz, Gaspar de la Peña y Juan Francisco Hidalgo. Por desgracia, las faltas en la documentación conservada no permiten establecer una cronología precisa ni rellenar la laguna existente entre el último año registrado de Juan Francisco Hidalgo como maestro mayor $(1681)^{2}$ y el nombramiento de Francisco Hurtado Izquierdo en 1697.

El objetivo del presente trabajo es profundizar en el conocimiento de la vida y obra de Sebastián Vidal, uno de los arquitectos que más tiempo ocupó el puesto, desde 1631 hasta $1654^{3}$. Se trata de una figura poco conocida de la que sólo se ha estudiado hasta ahora su faceta como retablista ${ }^{4}$. Es por ello que las fuentes que vamos a utilizar van a ser fundamentalmente documentales, procedentes del archivo de la catedral y de los protocolos notariales de Córdoba capital (Figura 1).

\section{NOTAS BIOGRÁFICAS}

Las noticias biográficas sobre el retablista y arquitecto Sebastián de Vidal que tenemos son bastante escasas. Sabemos que era portugués y natural de Montemoro-Novo, en el distrito de Évora ${ }^{5}$. Sus padres, Manuel Vidal e Isabel Martín, estaban supuestamente emparentados con el capitán general de Angola, André Vidal de Negreiros y pertenecían a las élites rurales ${ }^{6}$. Hemos de manejar estos datos sobre la condición social de sus progenitores con cierta cautela ya que proceden del expediente de limpieza de sangre incoado cuando su hijo Antonio accedió al cargo de racionero de la catedral de Córdoba en $1667^{7}$. Hay que tener en cuenta que, tal y como señala Aranda Doncel, los portugueses constituyen la colonia de extranjeros más numerosa en la capital cordobesa durante el siglo XVII y que en su mayoría se trata de

${ }^{1}$ Archivo de la Catedral de Córdoba (ACCo), Secretaría: Cuentas de la obra y fábrica de la santa iglesia catedral entre los años 1605 y 1695, cajas 4003, 4004, 4005, 4006 y tomos 4007, 4008 y 4009.

2 Moreno Hurtado, 2020.

${ }^{3}$ Este trabajo forma parte del proyecto de investigación en curso "Aproximación a la ciudad nobiliaria de los reinos de Córdoba y Sevilla en la Edad Moderna como tipología urbana", dentro del programa de doctorado en Historia, Historia del Arte y Territorio de la UNED.

${ }^{4}$ Raya Raya, 1987a: 33-35.

5 Testamento de Sebastián Vidal, Archivo Histórico Provincial de Córdoba (AHPCO), 20 de mayo de 1632, 10784P, f. 776v y Expediente de limpieza de sangre de Antonio Vidal, ACCo, Secretaría: Expedientes de limpieza de sangre, caja 5.028, sin foliar.

${ }^{6}$ Díaz Rodríguez, 2012: 186-187.

7 ACCo, Secretaría: Expedientes de limpieza de sangre, caja 5.028, sin foliar. 
inmigrantes que buscan una mejora de sus condiciones de vida ${ }^{8}$. Además, el hecho de que las averiguaciones genealógicas no se llevaron a cabo en Portugal sino en Badajoz facilitaría posibles manipulaciones y falsificaciones de los orígenes familiares.

Debió de llegar a Córdoba bastante joven ${ }^{9}$, aunque las noticias documentales más antiguas que hemos encontrado datan de mayo de $1619^{10}$. De acuerdo con el testamento que otorgó en 1632, contrajo matrimonio con Ana María de la Cerda hacia 1617 y tuvo con ella cinco hijos, Antonio, Isabel, Juana, Ana y Elena Vidal ${ }^{11}$. Según las declaraciones de los testigos interrogados en Córdoba en 1657 durante la elaboración del citado expediente de limpieza de sangre de su hijo Antonio, la esposa de Vidal utilizó también el nombre de Mariana Venegas ${ }^{12}$, que es con el que es nombrada en dicho documento. Este hecho está relacionado con su condición de hija natural de Fernando Carrillo Venegas e Isabel de Angulo, ambos pertenecientes a antiguos linajes de la nobleza cordobesa ${ }^{13}$. Puesto que sus padres se desentendieron de su crianza, se hizo cargo de ella el arcediano de Castro, Gonzalo Flores de Carvajal, hermano de un cuñado de su padre, que la llevó a casa del racionero Damián de Vargas "donde estuvo hasta que cassó" ${ }^{14}$. Gracias a su boda con Vidal "no entró de monja en Santa Clara donde la iban a meter"15. Esta estrecha relación de su esposa con la élite eclesiástica cordobesa debió, sin duda ayudarle en el despegue de su carrera profesional como retablista y escultor.

No tenemos tampoco certeza del momento en que se produjo su fallecimiento. A partir de 1652 las noticias documentales se cortan, lo que parece indicar que se ha marchado de la ciudad o que ha muerto. Los dos autores que más han estudiado su vida hasta ahora sitúan su deceso en años muy dispares. Llaguno dice que fue en $1653^{16}$, pero Raya lo retrasa hasta $1676^{17}$. La fecha mencionada por Llaguno se aproxima bastante a la que dan los testigos en las pruebas de limpieza de sangre de su hijo Antonio para su puesto en la catedral de Córdoba.

${ }^{8}$ Aranda Doncel, 2012: 65.

${ }^{9}$ El antiguo paje del inquisidor Miguel Jiménez Palomino lo conoció antes de casarse, cuando tenía "diez y ocho o veinte años". ACCo, Secretaría: Expedientes de limpieza de sangre, caja 5.028, sin foliar.

10 AHPCO, Protocolo de escrituras de Alonso Rodríguez de San Martín, 18 de mayo de $1619,16122 \mathrm{P}$, f. 802 r.

11 AHPCO, 20 de mayo de 1632, 10784P, f. 776v.

12 Alonso López dice que "la llamavan Mariana Venegas y que otros la llamavan Ana María"

${ }^{13}$ Díaz Rodríguez, 2012: 187.

${ }_{14}$ ACCo, Secretaría: Expedientes de limpieza de sangre, caja 5.028, sin foliar.

${ }^{15}$ ACCo, Secretaría: Expedientes de limpieza de sangre, caja 5.028, sin foliar.

${ }^{16}$ Llaguno y Amírola/Ceán Bermúdez, 1977: 191.

${ }_{17}$ Raya Raya, 2013: 888-889. Es probable que haya tomado la fecha que aparece en la lápida, que con toda probabilidad corresponde a la del fallecimiento del hijo. 
Varios de ellos declararon en 1667 que murió "abrá doze años"18. Según Nieto Cumplido todavía vivía a principios de 1654 y seguía siendo maestro mayor de la catedral, aunque ese mismo año fue sustituido en el cargo por Domingo de Mendigoitia $^{19}$. No hemos podido localizar su último testamento ni su inventario de bienes, que nos hubieran permitido saber la fecha y las circunstancias exactas de su defunción.

Fue sepultado frente a la portada de la capilla de san Antonio de la catedral. Junto a él, según la lauda fechada en 1676, se enterraron sus hijos, el racionero Antonio Vidal y sus hermanas (Figura 2) ${ }^{20}$.

\section{APROXIMACIÓN AL CATÁLOGO DE SUS OBRAS E INTERVENCIONES DOCUMENTADAS}

El primer encargo lo recibe en 1620 de Juan Chamizo Garrido, mayordomo de la capilla de las Ánimas del Purgatorio de la catedral, a su vez capilla funeraria del Inca Garcilaso de la Vega ${ }^{21}$. Consistía en hacer de yesería el último cuerpo de la cornisa sobre la portada, la bóveda exterior hasta la claraboya y los escudos del frontispicio, cobrando por todo ello mil reales ${ }^{22}$. Posteriormente completaría la decoración de la capilla, realizando por 50 reales dos cuadros con cartelas y agallones ${ }^{23}$ y tres bastidores forrados de tablas ${ }^{24}$.

Rafael Japón ha documentado su intervención en 1622 en la parroquia de Guadalcázar en la terminación del retablo mayor y de otro lateral ${ }^{25}$. En 1624, presentándose como maestro ensamblador, concierta con Juan Sánchez de Santana, familiar del santo oficio y hermano mayor de la cofradía de san Cristóbal y santa María Magdalena del hospital de la Lámpara, la hechura de un tabernáculo de madera de pino de Flandes para el altar mayor de la iglesia del hospital por 400 reales $^{26}$.

${ }_{18}$ ACCo, Expediente de limpieza de sangre de Antonio Vidal, Secretaría, caja 5028, $\sin$ foliar.

19 Nieto Cumplido, 2007: 422 y 543.

${ }^{20}$ Raya le atribuye la autoría del retablo de la capilla, Raya Raya, 2013: 889.

${ }^{21}$ De la Torre y del Cerro, 2012: 156-163.

${ }^{22}$ AHPCO, Protocolo de escrituras de Alonso Rodríguez de San Martín, 9 de noviembre de 1620, 16125P, ff. 1611r-1613r.

${ }^{23}$ Se trata de una "labor de salientes como gajos, de relieves que dejan entre sí partes hundidas, las cuales a veces, se rehúnden más para enriquecer la talla”. Sáenz de la Calzada Gorostiza, 1956: 218-219.

${ }^{24}$ AHPCO, Protocolo de escrituras de Gonzalo Fernández de Córdoba, 21 de abril de 1622, 10774P, ff. 526r-526v.

25 Japón Franco, 2013: 54.

${ }_{26}$ AHPCO, Protocolo de escrituras de Alonso Rodríguez de San Martín, 11 de septiembre de 1624, 16133P, ff. 804r-806v. Esta pieza no ha llegado hasta nuestros días. 
A finales de ese mismo año de 1624, tenemos noticias del encargo de "la pintura, ensamblaje, estofado y encarnado y dorado" de un retablo y tabernáculo para el altar de Nuestra Señora del Rosario para los "vecinos y cofrades de la cofradía del Rosario de la villa de Posadas", según los términos que el difunto regidor Alonso Díaz de Belcázar había dispuesto y dotado mediante escritura otorgada ante Francisco de Palma ${ }^{27}$, escribano de la villa de Posadas ${ }^{28}$.

No volvemos a encontrar nuevos encargos hasta que en 1626 concertó con el marqués de El Carpio la hechura de un retablo para la iglesia del desaparecido convento franciscano de san Francisco del Monte, en la villa de Adamuz, con un presupuesto total de 240 ducados $^{29}$. Sabemos que a mediados de ese año el retablo ya estaba terminado gracias a una carta de pago otorgada para zanjar cuentas con el tesorero del citado marqués. Es precisamente a partir de este momento cuando Vidal aparece descrito como arquitecto y no como ensamblador, tal y como ocurre en otra de junio del mismo año de 1626 en la que contrata con Juan Lorenzo de Vargas, rector y obrero de la iglesia mayor de Castro del Río, un monumento de madera de borne y pino según una traza elaborada por él mismo, siendo el plazo de ejecución hasta fin de año y el precio el que tasaran dos maestros una vez acabada la obra, uno nombrado por Vidal y el otro por el obrero de la iglesia ${ }^{30}$.

A mediados del año siguiente de 1627 va a concertar con el racionero Rodrigo Muñoz Bermúdez la realización del retablo de santa Úrsula y santa Francisca Romana (Figura 3) para su capilla de la catedral de Córdoba por 5.200 reales $^{31}$, que no terminaría de cobrar hasta $1633^{32}$.

Según Raya, desde 1629 desempeñó las funciones de maestro mayor de la catedral cordobesa, aunque su nombramiento oficial no tuvo lugar hasta el 21 de marzo de 1631. A partir de mayo de 1632 se encargó de continuar el retablo mayor

${ }^{27}$ Se trata del sobrino y heredero de Gonzalo Silvestre, amigo del inca Garcilaso de la Vega. De la Torre y del Cerro, 2012: 21-22 y 57-60.

${ }^{28}$ Todos estos datos figuran en la escritura de fianza que otorgaron el pintor Andrés Fernández y su tercera esposa, María de Rivas. AHPCO, Protocolo de escrituras de Marcos Damián, 1 de diciembre de 1624, 15875P, ff. 537r-538v. Esta pieza tampoco se conserva.

${ }_{29}$ AHPCO, Protocolo de escrituras de Gonzalo Fernández de Córdoba, 3 de junio de 1626, 10778P, ff. 499r-499v.

${ }^{30}$ AHPCO, Protocolo de escrituras de Andrés Rodríguez de la Cruz, 4 de junio de 1626, 14671, ff. 619r-621r. La obra está en paradero desconocido.

31 AHPCO, Protocolo de escrituras de Gonzalo Fernández de Córdoba, 19 de agosto de 1627, 10779P, ff. 877r-879r. Noticia publicada por Aroca Lara, 1986: 180.

32 AHPCO, Protocolo de escrituras de Gonzalo Fernández de Córdoba, 8 de marzo de 1633, 10786P, ff. 344r-344v. Mediante carta de pago Sebastián Vidal, que firma ya como arquitecto y maestro mayor de las obras de la catedral, recibe del doctor Diego Bermúdez, depositario de los bienes de su hermano, el difunto Rodrigo Muñoz Bermúdez, los 400 reales que aún se le debían. 
siguiendo las trazas de Alonso Matías ${ }^{33}$. De este modo en 1633, como "maestro mayor de obras de la d[ich]a santa iglesia [catedral] y fábrica de su obispado" y mediante un poder otorgado por los diputados del retablo mayor, concierta con el cantero egabrense Cristóbal del Castillo el suministro de la piedra de jaspe que se necesitase para el segundo cuerpo del retablo y en otras partes del edificio ${ }^{34}$. Estos trabajos se prolongarían bastante ya que en los libros de fábrica aparecen reflejados cuatro pagos a Sebastián Vidal en 1645 y dos en 1646 por el importe de la terminación de las obras del retablo mayor ${ }^{35}$.

Desde el momento en que fue nombrado maestro mayor dejó de trabajar como retablista y comenzó su carrera como arquitecto tracista, diseñando y estableciendo las condiciones de ejecución de obras, tanto arquitectónicas como retablísticas, cuya realización material corría a cargo de otros maestros de menor categoría. El primero de estos encargos lo realizó en 1632 para la capilla funeraria del capitán Benavides en la parroquia de Santa Marina de Córdoba, cuyo patronato, según las disposiciones testamentarias del fundador, había recaído en el cabildo catedralicio. Sebastián Vidal dio las condiciones para los trabajos de albañilería, que ejecutaron Bartolomé Muñoz y Marcos Ruiz, y también para los de cantería, que llevaron a cabo Mateo López de León y Cristóbal del Castillo, e incluso para los de policromía y dorado, que corrieron a cargo de Cristóbal Vela. Estableció los plazos, supervisó la marcha de los trabajos e incluso actuó como testigo en la firma de los diversos contratos de obra ${ }^{36}$.

A principios de 1635 se documenta su labor como tracista de una pieza desaparecida, el sagrario de madera de pino que Antonio de Santa Cruz, maestro arquitecto y vecino de la collación de Santa María, concertó con el convento de monjas de nuestra señora de la Encarnación por un precio de 1.430 reales $^{37}$.

A partir de 1636 empieza a haber también noticias documentales sobre su actividad como maestro mayor de obras de la ciudad, emitiendo informes sobre la marcha de las obras de reparación del puente sobre el Guadalquivir que se habían adjudicado al maestro albañil Baltasar de los Reyes en mayo de $1634^{38}$. Desde entonces su

${ }^{33}$ Raya Raya, 1987a: 33.

${ }_{34}$ AHPCO, Protocolo de escrituras de Gonzalo Fernández de Córdoba, 21 de mayo de 1633 , ff. $851 \mathrm{v}-855$ r. Incluye el poder otorgado el 13 de mayo del mismo año por el arcediano de Pedroche.

${ }_{35}$ ACCo, Secretaría: Cuentas de la obra y fábrica de la santa iglesia catedral, caja 4004, ff. 46v-47r.

36 Pérez Cano, 1998: 257-269. Según Raya, también dio las trazas del retablo, que se construyó entre 1635 y 1640 y se decoró con pinturas de Antonio del Castillo. Raya Raya, 1987: 34. La capilla sirve actualmente de sede a la cofradía cordobesa del Resucitado.

${ }^{37}$ AHPCO, Protocolo de escrituras de Gonzalo Fernández de Córdoba, 10790P, 23 de enero de 1635 , ff. 51r-56r.

38 Archivo Municipal de Córdoba (AHMCo), Provisiones y autos sobre reparación del puente mayor. Años 1.627 a 1.639. AH040601-SF-C-00108-072. Citado por Sainz y Gutiérrez, 1894: 55. 
actividad constructiva se diversifica con la incorporación de nuevos campos de actuación que compagina con la maestría mayor de las obras de la catedral. Así, en agosto de ese mismo año de 1636 dio las condiciones para la reparación de la desaparecida casa de comedias que era propiedad del municipio ${ }^{39}$. En 1637 emite nuevos informes sobre la marcha de las obras del puente de Córdoba ${ }^{40}$ dirige la reparación de los agujeros y portillos de las murallas de la ciudad ${ }^{41}$, y traza una planta y da las condiciones para los reparos del molino de Lope García ${ }^{42}$ propiedad del cabildo de la catedral de Córdoba, que se adjudicaron en julio de 1638 al cantero Juan García ${ }^{43}$. En 1639 está documentada su actividad como tracista en dos obras de naturaleza muy diversa, ya que diseña y da las condiciones para el retablo mayor de la iglesia del conventual del Carmen calzado (Figura 4), que fue realizado por Pedro Freila de Guevara ${ }^{44}$, y también para unos nuevos trabajos de reparación en el puente de Córdoba de los que se conservan las trazas, los únicos dibujos originales de Vidal que han llegado hasta nosotros (Figura 5) ${ }^{45}$. En enero de 1640 va a dirigir por encargo del obispado unos

39 AHMCo, expedientes seguidos para el reparo de la casa de las comedias durante los años de 1610 a 1636, AH050601-SF-C-00116-013, 20 de agosto de1636, ff. 69r-69v. Transcrito y editado por García Gómez, 1990: 128-129. El autor transcribe erróneamente el nombre como Sebastián Bides. La firma que aparece en el documento, sin embargo, es con total seguridad la de Vidal.

${ }^{40}$ Sainz y Gutiérrez, 1894: 55.

41 AHPCO, Protocolo de escrituras de Gonzalo Fernández de Córdoba, 10794P, 5 de junio de 1637, ff. 515r-515v. Sebastián Vidal, maestro mayor de obras de la ciudad otorga carta de pago de 500 reales a cuenta de dichas obras a favor de Juan Fernández de Castro, tesorero de las obras de la ciudad.

42 ACCo, Actas Capitulares, Libro 49, viernes 6 de marzo de 1637, ff. 12v-13r. "Sebastián Bidal maestro $\mathrm{m}\left[\mathrm{ay}{ }^{\text {or }}\right.$ de esta s [an] ${ }^{\text {ta }}$ Ygle [sia] trajo una planta de la presa y molino de Lope García y hiço relación de remedio que se debe tomar para el reparo del daño que tienen $\mathrm{d}$ [ic] hos molinos y presas y que esta obra convenía que se hiciye a jornal y no a destajo".

${ }^{43}$ AHPCO, Protocolo de escrituras de Andrés Rodríguez, 14695P, 31 de julio de 1638, ff. 922r-923r. Escritura otorgada por Juan García, maestro cantero y albañil, obligándose con el deán y cabildo de la santa iglesia catedral a efectuar obras y reparos en su molino llamado de Lope García por el precio de 3.500 reales. El cantero se compromete a cumplir las condiciones establecidas por Vidal, que firma como maestro mayor de obras de la catedral y de la ciudad.

${ }_{44}$ AHPCO, Protocolo de escrituras de Gonzalo Fernández de Córdoba, 3 de septiembre de 1639, 10797P, ff. 969v-971r. El comitente del retablo fue Pedro Gómez de Cárdenas, comendador del tesoro de la orden de Calatrava, señor de Villanueva del Rey y caballero veinticuatro de Córdoba. Pedro Freila hizo la parte arquitectónica y escultórica del retablo, en el que se colocaron lienzos de Valdés Leal.

45 AHMCo, AH040601-SF-C-00108-072. La traza representa un emparrillado de tablones que se debía clavar con estacas en el lecho del río, en el hueco del arco. En la parte izquierda del dibujo, rotulado con la letra T, aparece la retícula de "caxas" con el relleno de arena y cal que debía llevar, y sobre el que se colocaría un recubrimiento exterior, tal y 
arreglos de emergencia en la iglesia de la villa de Conquista con un presupuesto de 160 ducados y una duración estimada de tres meses ${ }^{46}$. En mayo de 1641, por encargo del Consejo Real se obliga a hacer dos nichos y dos urnas de piedra para la capilla real de la catedral de Córdoba, aunque al final el proyecto no llegó a realizarse ${ }^{47}$. Ese mismo año de 1641, en calidad de maestro mayor de obras de la ciudad, dirigió la reparación de la casa de comedias propiedad del cabildo municipal ${ }^{48}$.

En los años siguientes solo tenemos documentada su actividad como proyectista de edificios religiosos. En julio de 1642 da la traza y las condiciones para la reconstrucción de las techumbres y bóvedas del coro alto de la iglesia del desaparecido convento cordobés de monjas dominicas de Santa María de Gracia, destruido por un incendio el Sábado Santo de aquel mismo año ${ }^{49}$. El contrato se adjudicó al maestro albañil Juan Francisco Hidalgo, que con el tiempo llegaría también a ser maestro mayor de la ciudad y de la catedral, aunque también presentaron postura Miguel de Anguita, Gaspar de los Reyes y Juan de la Vega ${ }^{50}$. En 1644 dio la traza y las condiciones para unas reformas que dotasen de mayor unidad estilística a la capilla mayor del convento de Santa Isabel de los Ángeles, propiedad de los señores de Villaseca. En este caso actuó también como testigo en el contrato de obra escriturado por los maestros de cantería Mateo López Niño y Antonio Rodríguez. Se trataba de remodelar el testero del altar erigiendo un arco a imagen y semejanza del arco toral "ymitando en el todo y en cada una de sus partes su labor, de suerte que la obra quede de un genero" ${ }^{51}$. Además, según Raya, "proyectó la reforma del

como se ve en la parte derecha, rotulado con la letra R. Para "enfrenar la fuerza del curso de las aguas" y proteger esta estructura también se debía hacer una zona triangular de cascajo muy grueso, rotulada con la letra $\mathrm{C}$.

${ }_{46}$ AHPCO, Protocolo de escrituras de Juan de Paniagua, 18 de enero de 1640, 11757P, ff. $58 \mathrm{r}-63 \mathrm{v}$.

47 "Los arcos, las jambas y las impostas habían de ser de jaspe de leche y sangre, y blanco y negro de las canteras del valle de Luque; que las urnas se habían de componer de basas, cuerpo y tapas de jaspe amarillo y encarnado con pintas negras de la cantera de Cabra y para los cojines se había de buscar piedra brocadete y para las coronas jaspe amari1lo, todo sin otra mezcla de color, de las mismas canteras. Los embutidos de piedra negra habían de ser de la cantera de Hornachuelos, sin mezcla alguna blanca". Ramírez de las Casas Deza, 1862 (1923): 78.

${ }^{48}$ AMCo, Actas capitulares del 21 de octubre de 1641, f. 529v. Documento transcrito y publicado en García Gómez, 1999: 232.

49 AHPCO, Protocolo de escrituras de Andrés de la Peña, 12 de julio de 1642, 10107P, ff. $874 \mathrm{r}-876 \mathrm{v}$.

${ }^{50}$ AHPCO, Protocolo de escrituras de Andrés de la Peña, 12 de julio de 1642, 10107P, ff. $877 \mathrm{r}-881 \mathrm{v}$.

${ }_{51}$ AHPCO, Protocolo de escrituras de Nicolás Damas de Luque, 28 de marzo de 1644, 10112P, f. 627. El documento completo fue transcrito y publicado por Aguilar Priego, 1954: 215-219. Luque Carrillo le atribuye también la co-autoría de la bóveda esquifada que cubre la capilla en compañía del escultor Bernabé Gómez del Río entre 1644 y 1655, Luque 
Santuario de Nuestra Señora de Villaviciosa" ${ }^{52}$. En 1647 diseña la portada del convento de la Santísima Trinidad de Córdoba (Figura 6), que llevaron a cabo Juan García, cantero y escultor, y Pedro de la Toba, sacador de piedra y cantero, con materiales extraídos de las canteras del Arroyo del Moro ${ }^{53}$. Se trata de una fachada de grandes dimensiones derivada de los modelos de fray Lorenzo de San Nicolás ${ }^{54}$.

En 1648 de nuevo como maestro mayor de las obras de Córdoba, dirige unos trabajos de reparación por valor de 1.185 reales en el desaparecido Corral de los Ahogados, junto a la puerta del puente ${ }^{55}$. Sus últimas obras conocidas están nuevamente relacionadas con la catedral. En 1650 dio las trazas para la remodelación de la puerta del Perdón que ejecutaron los canteros Bartolomé Muñoz de Morales y Francisco Manuel de Castro ${ }^{56}$. Finalmente, en 1652 termina el tabernáculo del altar mayor de la catedral sobre las trazas que había dejado Alonso Matías ${ }^{57}$.

\section{CONDICIÓN SOCIAL}

Aunque no tenemos datos referentes a su formación, sabemos que Sebastián Vidal pertenecía a la categoría de escultor-arquitecto ${ }^{58}$, amén de otros maestros

Carrillo, 2019: 30. Por el contrario, en los datos publicados por Aguilar Priego aparece como único responsable Gómez del Río y se establece que "todo lo tocante a la bobeda se a de hacer conforme a un dibujo que para el intento esta hecho questa firmado del dicho don Luis [Gómez, señor Villaseca, el comitente] y Bernave Gomez". Aguilar Priego, 1954: 221-224. La iglesia permanece actualmente cerrada tras la marcha de la comunidad religiosa.

52 Raya Raya, 2013: 888-889.

53 AHPCO, Protocolo de escrituras de Cristóbal de Orbaneja, 13 de abril de 1647, 11009P, ff. 285r-286v. Noticia publicada por Aroca Lara, 1986: 187.

${ }^{54}$ Presenta el almohadillado que el tratadista agustino denomina "campos relevados", así como frontones curvos partidos y frontones triangulares adornados con pirámides rematadas en bolas, encerrados entre dos pilastras gigantes sobre los que se levanta un gran frontispicio triangular con entablamento toscano y óculo central con pirámides pequeñas; a los lados hay dos cuerpos que repiten, a menor escala, el esquema central. Para Pita Andrade muestra "libertades en la manera de entender las proporciones". Kubler en cambio la juzgó muy negativamente, afirmando que "las proporciones de fray Loreno están deformadas por ejecutantes aficionados". Pita Andrade, 1983: 516 y Kubler, 1957: 81.

${ }_{55}$ AHPCO, Protocolo de escrituras de Jacinto Fernández de Aranda, 16064P, 17 de diciembre de 1648, ff. 818r-818v. En el solar del desaparecido Corral de los Ahogados se levanta actualmente el triunfo de san Rafael.

${ }_{56}$ AHPCO, Protocolo de escrituras de Juan de Mansilla, 10 de agosto de 1650, 11864P, ff. 304r-305v. Sobre esta reedificación del coronamiento de la puerta, según traza de Vidal, Domingo de Mendigoitia erigió en 1652 un campanario provisional, utilizado mientras no se reparaba la torre, Nieto Cumplido, 2007: 596, 607 y 609. Los trabajos de reparación de la torre y diversas intervenciones en el siglo XVIII han transformado la obra que diseñó Vidal.

${ }^{57}$ Romero de Torres, 1934: 295. AHPCO, 11864P, ff. 304r-305v.

58 García Morales,1991: 191. 
mayores de la catedral cordobesa que lo antecedieron, como el ya citado Pedro Freila. Ambos son escultores y ensambladores que practican la arquitectura y que aparecen mencionados en los documentos notariales desempeñando una $\mathrm{u}$ otra profesión indistintamente ${ }^{59}$. Sebastián Vidal, en las primeras escrituras conocidas, correspondientes a los años 1619 y 1620, se denomina maestro de ensamblaje o ensamblador ${ }^{60}$. Sin embargo, a partir de 1621 se le designa como arquitecto $^{61}$, y es precisamente con ese epíteto cuando alcanza la máxima categoría profesional, la de maestro mayor.

Sin duda, en aquellos momentos, en ciudades como Córdoba, que eran sedes episcopales, el puesto más prestigioso para un arquitecto era el de maestro mayor de las obras de la catedral, la institución que, pese a las dificultades de la época, era capaz de movilizar mayores recursos para empresas constructivas y ofrecía el salario más alto ${ }^{62}$. Con frecuencia, tal y como hiciera Sebastián Vidal, acumulaba también los cargos de maestro mayor de las obras del obispado ${ }^{63}$ y de la ciudad ${ }^{64}$.

La visibilidad que otorgaban esos empleos hacía que recibieran peticiones de consejo, inspección o tasación de obras de gran envergadura y complejidad procedentes de instituciones y particulares. Sin embargo, solo hemos logrado localizar dos comisiones de ese tipo realizadas por Vidal. La primera, en 1628, es anterior a su nombramiento como maestro mayor catedralicio. Consistió en la tasación de las obras realizadas en el convento de los carmelitas de Guadalcázar ${ }^{65}$. La segunda, en 1642, la realiza junto a Domingo de Mendigoitia, redactando un informe en el que daba su parecer sobre el retablo del Carmen que Pedro Freila ejecutó a partir de sus propias trazas ${ }^{66}$.

${ }^{59}$ Pedro Freila se intitula "escultor" y "arquitecto" indistintamente. Valverde Madrid, 1977: 169-200.

${ }^{60}$ AHPCO, Protocolo de escrituras de Alonso Rodríguez de San Martín, 18 de mayo de 1619, 16122P, f. 802r y 16125P, ff. 1611r-1613r.

${ }^{61}$ AHPCO, Protocolo de escrituras de Gonzalo Fernández de Córdoba, 16 de marzo de 1621, 10773P, f. 320r.

${ }^{62}$ Según Llaguno, el vizcaíno Blas de Masavel fue nombrado maestro mayor de la catedral en 1606, con un salario anual de 40.000 maravedíes y 6 reales al día mientras durasen las obras que se hacían en aquel momento. Llaguno y Amírola/Ceán Bermúdez, 1977: 136.

${ }^{63}$ Dos de los antecesores de Vidal en el cargo, Hernán Ruiz III (1534-1606) y Blas de Masavel (i-?), aparecen denominados en algunas escrituras notariales como "maestro mayor de las obras de Córdoba y su obispado". AHPCO, Protocolo de escrituras de Alonso Rodríguez de la Cruz, 16 de febrero de 1576, 15102P, f. 100r y Protocolo de escrituras de Francisco Martínez de Molina, 21 de septiembre de 1608, f. 728r.

${ }^{64}$ Es el caso Pedro Freila de Guevara, el antecesor de Vidal, Valverde Madrid, 1977:169-200. Entre sus sucesores, podemos citar a Juan Francisco Hidalgo. Llaguno y Amírola/Ceán Bermúdez, 1977: 58, vol IV y Sainz y Gutiérrez, 1894: 152.

${ }^{65}$ Cerrato Mateos, 2006:79.

${ }^{66}$ Vigara Zafra, 2011:67. 
Hace ya algunos años que Martín González constató la pulsión hacia el ascenso social de los artistas en la Castilla del siglo XVII, acreditada en la búsqueda de títulos y distinciones ${ }^{67}$. En el caso de Sebastián de Vidal, un inmigrante extranjero, sus cargos de maestro mayor de los dos cabildos de la ciudad, el civil y el eclesiástico, representan la "culminación de una trayectoria profesional" en palabras de Aranda Doncel ${ }^{68}$. Puesto que percibía unos salarios estables y acordes con su categoría laboral, hemos de suponer que gozaba de una situación económica desahogada, aunque la falta de datos nos impide establecer conclusiones definitivas sobre su grado de enriquecimiento ${ }^{69}$. Tenemos sin embargo algunas noticias que parecen indicar que, al menos durante un tiempo, emprendió algún tipo de actividad comercial como fuente de ingresos complementaria ${ }^{70}$, un recurso que emplearon otros artistas barrocos, tanto en Córdoba ${ }^{71}$ como en Sevilla ${ }^{72}$.

Otra de las marcas de prestigio mencionadas por Martín González es el lugar de residencia y de enterramiento del $\operatorname{artista}^{73}$. Tener casa en propiedad solo estaba al alcance de los artistas más exitosos, pues la mayoría vivían de alquiler. Y precisamente esta última circunstancia concurrió en la vida sobre Sebastián Vidal, del que tenemos documentados varios cambios de domicilio de nuestro protagonista durante los primeros años de su carrera, antes de conseguir la maestría mayor ${ }^{74}$. Se trata de casas alquiladas con contratos de arrendamiento bianuales en las calles que rodean el recinto catedralicio, una elección obvia ya que además de la ubicación prestigiosa, ofrece la proximidad al lugar donde surgen las empresas artísticas más importantes del momento. El primero de estos arrendamientos lo hizo en 1619 sobre unas casas en las inmediaciones de la catedral, frente al Caño Gordo, por dos años a Pedro Fernández de Valenzuela y por una renta anual de 22 ducados $^{75}$. En

${ }^{67}$ Martín González, 1984: 198.

${ }_{68}$ Aranda Doncel, 1984: 182.

${ }^{69} \mathrm{Su}$ antecesor en esos cargos, Pedro Freila, que disfrutó de la misma categoría profesional y recibió numerosos encargos, murió agobiado por múltiples problemas económicos. Valverde Madrid, 1977: 173.

${ }^{70}$ En 1637 arrendó durante un año una tienda en la calle de la puerta el Perdón al presbítero Andrés Agustín de Savariego por una renta anual de 12 ducados. AHPCO, Protocolo de escrituras de Gonzalo Fernández de Córdoba, 21 de junio de 1637, 10794P, f. 587r.

${ }^{71}$ El pintor y escultor Andrés Fernández, padre de Dionisio y Francisco de Rivas y amigo personal de Sebastián Vidad, fue arrendatario del mesón del Sol, propiedad del cabildo catedral de Córdoba, desde 1601 hasta su fallecimiento en 1626. Romero de Torres, 1933: 35.

72 José García, maestro mayor del arzobispado y del concejo hispalense, perteneciente a una generación posterior Vidal, poseyó una "tienda de refino". Cruz Isidoro, 1993: 105.

${ }_{73}$ Martín González, 1984: 200-203.

${ }^{74}$ En Sevilla por las mismas fechas era bastante frecuente que los artistas que vivían de alquiler cambiaran frecuentemente de vivienda. Falcón Márquez, 2013: 71. Faltan estudios específicos sobre el tema en Córdoba.

${ }^{75}$ AHPCO, Protocolo de escrituras de Alonso Rodríguez de San Martín, 16122P, f. 802r. 
1621, también por dos años, arrendó a Catalina de Cañete unas casas junto a la torre, por una renta anual de 24 ducados $^{76}$. En 1625 renovó por cuatro años el arrendamiento de unas casas frente a la calleja de Quero (denominada actualmente de la Hoguera ${ }^{77}$, pero al año siguiente se mudó a otras pertenecientes a Inés de Guzmán, comprometiéndose a pagar una renta de 38 ducados anuales durante cuatro años ${ }^{78}$. A partir de esa fecha no hemos podido encontrar más noticias sobre los domicilios de nuestro arquitecto. Es probable que el cabildo le facilitase vivienda una vez alcanzada la maestría mayor de la catedral, como haría años más tarde con Francisco Hurtado Izquierdo ${ }^{79}$, una práctica común de los cabildos catedralicios en el reino de Castilla, al menos durante los siglos XV y XVI ${ }^{80}$. Por otra parte, según el testimonio de Domingo de Mendigoitia mencionado anteriormente, Vidal falleció en su domicilio en la calle del Romero, en el barrio de la judería de Córdoba ${ }^{81}$. Puesto que es la misma casa en la que habitaba entonces su hijo Antonio, es plausible que se tratase de una propiedad que éste último hubiera heredado de su progenitor.

En cuanto al enterramiento, Sebastián Vidal sacó provecho de su situación laboral para conseguir un enterramiento en uno de los espacios funerarios más prestigiosos de la ciudad, la catedral. En el testamento que dictó en 1632, mandó que su cuerpo fuera sepultado "en la iglesia catedral de esta ciudad en la sepultura que me dieren" 82 , un deseo que se cumplió tras su fallecimiento, ya que fue enterrado a los pies de la capilla de San Antonio de Padua ${ }^{83}$. Aunque desde el siglo XV era común en la corona de Castilla que los maestros mayores catedralicios fueran enterrados en los templos para los que trabajaban ${ }^{84}$, en el siglo XVII esta prebenda no se prodigó en la catedral de Córdoba ${ }^{85}$.

${ }^{76}$ AHPCO, Protocolo de escrituras de Gonzalo Fernández de Córdoba, 16 de marzo de 1621, 10773P, f. 320r.

77 AHPCO, Protocolo de escrituras de Bartolomé Tercero, 3 de marzo de 1625 , 12785P, f. 195r.

${ }^{78}$ AHPCO, Protocolo de escrituras de Gonzalo Fernández de Córdoba, 16 de abril de 1626, 10778P, f. 339r.

79 AHPCO, Protocolo de escrituras de Diego de Pineda y Vargas, 11 de noviembre de 1697, 16048P, f. 924r.

${ }^{80}$ Alonso Ruiz, 2012: 234.

${ }^{81}$ ACCo, Expediente de limpieza de sangre de Antonio Vidal, Secretaría, caja 5028, $\sin$ foliar.

${ }^{82}$ AHPCO, Protocolo de escrituras de Gonzalo Fernández de Córdoba, 20 de mayo de 1632, 10784P, ff. 775r-777r.

${ }^{83}$ Raya Raya, 2013: 888-889.

${ }^{84}$ Alonso Ruiz, 2012: 240.

${ }^{85}$ De hecho, solo hemos documentado el caso de Sebastián Vidal. A modo de ejemplo, su antecesor, Pedro Freila, fue enterrado en la parroquia de san Pedro. Valverde Madrid, 1977: 173. Uno de sus sucesores, Bartolomé Muñoz, pidió en su testamento de 1659 enterrarse en el convento de los mínimos de Córdoba, Nuestra señora de la Victoria, en la 


\section{RELACIONES SOCIALES CON CLIENTES Y OTROS ARTISTAS}

Los documentos muestran que la relación de Sebastián Vidal con el clero catedralicio no era meramente profesional. En el testamento que hizo en 1632, uno de los dos albaceas que elige es el deán Gonzalo de Castro Toboso ${ }^{86}$, uno de los miembros más destacados del cabildo catedralicio de la época y que ese mismo año apadrinó a su hijo Antonio cuando fue bautizado en el sagrario de la catedral ${ }^{87}$. Tal y como comentábamos al principio, su matrimonio contribuyó de manera decisiva a fundamentar estas buenas relaciones. Gracias a ellas se le permitió compaginar su trabajo en la catedral con la dirección de las obras del ayuntamiento de Córdoba.

Lo poco que sabemos sobre las relaciones sociales de Sebastián Vidal está vinculado mayoritariamente con los contactos que mantuvo con otros artistas por motivos laborales ${ }^{88}$, y que en algunos casos dieron pie a lazos de amistad que podemos rastrear en las escrituras notariales cuando los implicados actúan como testigos, fiadores o albaceas.

De este modo podemos deducir los vínculos existentes entre Vidal y el pintor y mesonero Andrés Fernández, el padre de Felipe y Dionisio de Rivas, que junto a su mujer, María de Rivas, hizo de avalista en el contrato del desaparecido retablo que concertó Sebastián Vidal para la villa de Posadas en 1624. Dos años más tarde, Vidal va a aparecer como testigo en el último testamento de Fernández ${ }^{89}$.

No es este el único testamento en el que aparece mencionado Vidal. En 1648 el cantero Mateo López Niño lo designó como uno de sus albaceas testamentarios. Pero este no es un testimonio aislado, sino que la relación laboral entre ambos está documentada por primera vez en 1644, cuando López ejecuta las trazas de Vidal para la capilla de los señores de Villaseca en el convento de Santa Isabel de los Ángeles, y Vidal actuó como testigo en las escrituras notariales que López tuvo que firmar. Pese a ello Vidal presentó su renuncia ante notario por hallarse muy ocupado y no poder cumplir con las obligaciones que conllevaba el ser albacea ${ }^{90}$.

sepultura de sus padres y abuelos. AHPCO, Protocolo de escrituras de Cristóbal de Orbaneja, 6 de abril de 1659, 11022P, ff. 243r-245v.

${ }^{86}$ Fue deán durante 30 años, desde 1619 hasta su muerte en 1649. Gómez Bravo, 1778: 594 y 654 .

${ }^{87}$ ACCo, Secretaría, caja 5028, sin foliar. Dato publicado por Díaz Rodríguez, 2012: 187.

${ }^{88}$ Sólo encontramos una referencia a un personaje de la nobleza local, Alonso Fernandez de Mesa y de Argote, primer señor del Chanciller, que aparece designado como el segundo de sus albaceas cuando testó en 1632. No disponemos de más datos sobre el origen y la naturaleza de su relación. AHPCO, 20 de mayo de 1632, 10784P, f. 776v.

${ }^{89}$ Romero de Torres, 1936: 39.

90 AHPCO, Protocolo de escrituras de Nicolás Damas de Luque, 20 de mayo de 1632, 10126P, ff. 553r-553v. 
Cierto es que no siempre es posible deducir la existencia de vínculos que trasciendan la relación meramente laboral a partir de los testimonios que han llegado hasta nosotros ${ }^{91}$, aunque de forma excepcional también nos encontramos con el testimonio directo de un artista, concretamente el vasco Domingo de Mendigoitia, que declara que "le trató y comunicó mui familiarmente porque [...] era del mismo gremio de escultor y arquitecto" $"$

\section{A MODO DE CONCLUSIÓN}

Los autores que se han ocupado hasta ahora de la figura de Sebastián Vidal ofrecen opiniones dispares sobre su valía. Así, Ortí Belmonte lo sitúa entre "los grandes arquitectos" que trabajan en Córdoba durante la Edad Moderna ${ }^{93}$, y más recientemente, Díaz Rodríguez lo considera "el maestro de obras más importante de la catedral desde los tiempos de los Hernán Ruiz un siglo atrás"94. Para Raya por el contrario es "un maestro poco amigo de las innovaciones, que prefiere los esquemas conocidos" "Sainz Gutiérrez ofrece un juicio crítico sobre su capacidad como ingeniero para apreciar el estado del puente mayor sobre el Guadalquivir ${ }^{96}$. Sin duda el más crítico al juzgarlo fue $\mathrm{Kubler}^{97}$, que al analizar una de sus obras de mayor envergadura, la fachada del convento cordobés de los trinitarios, lo considera un ejecutante aficionado de las fórmulas de fray Lorenzo de San Nicolás.

Por nuestra parte, consideramos que fue un artista polifacético, al compaginar sin dificultad los campos de la ensambladura, la arquitectura y la ingeniería civil. De hecho, aunque terminó su carrera trabajando en el mundo de la construcción, durante sus primeros años en Córdoba se dedicó a la escultura. Esto lo convierte en un ejemplo prototípico de arquitecto-artista ${ }^{98}$, una figura que abundó entre los maestros mayores de la catedral de Córdoba durante la primera mitad del siglo XVII. También fueron arquitectos-artistas, relacionados con la escultura, Pedro Freila, su antecesor, y Domingo de Mendigoitia, su sucesor.

${ }^{91}$ Resulta evidente que tuvo que tratar con Pedro Freila de Guevara cuando éste ejecutó su diseño para el retablo del Carmen, pero no tenemos muestras de ello. También sabemos que en torno a 1646 y durante alguno de los viajes que realizó a Granada para traer y ajustar piedra de Filabres con destino al retablo mayor de la catedral, debió de mediar en el encargo que el cabildo catedralicio cordobés hizo a Alonso de Mena de una escultura de un cordero de piedra para el sagrario. No tenemos ninguna otra evidencia que vuelva a relacionar a ambos artistas. Romero de Torres, 1934: 296.

${ }_{92}$ ACCo, Secretaría: Expedientes de limpieza de sangre, caja 5.028, sin foliar.

${ }_{93}$ Ortí Belmonte, 1980: 114.

${ }^{94}$ Díaz Rodríguez, 2012: 187.

${ }_{95}$ Raya Raya, 1987a: 35.

96 "Vidal se corrió de ligero al asegurar que no debía haber concavidades debajo del agua". Sainz y Gutiérrez, 1894: 56.

${ }^{97}$ Kubler, 1957: 81.

98 Véase al respecto Blasco Esquivias, 1991: 20-34. 
Aunque la falta de noticias nos impide saber dónde tuvo lugar su aprendizaje o formación, son evidentes la influencias que sobre él ejercieron el jesuita Alonso Matías y el agustino fray Lorenzo de San Nicolás, a través del contacto directo con la obra magna del primero, el retablo mayor de la catedral de Córdoba, y a través de la lectura de la primera parte del tratado Arte y uso de Architectura del segundo. Es incluso posible que llegase a conocer personalmente al hermano Matías antes de su salida de Córdoba. Los rasgos estilísticos de las obra retablísticas y arquitectónicas que han llegado hasta nuestros días muestran la progresiva evolución desde el tardomanierismo que caracteriza al contexto artístico cordobés de principios del siglo XVII, hacia un repertorio decorativo con rasgos de mayor volumen y movimiento, que anuncian ya la transición hacia un barroco pleno ${ }^{99}$. Este hecho, junto a la asimilación de las ideas del tratado de fray Lorenzo de San Nicolás, nos lleva a considerarlo como un arquitecto protobarroco ${ }^{100}$.

Además, los documentos que han servido para elaborar este trabajo indican que llegó a alcanzar una relativa importancia en el panorama artístico de la Córdoba de la primera mitad del siglo XVII, y que, como maestro mayor de la catedral y del ayuntamiento, estuvo implicado en gran parte de las empresas artísticas más importantes del momento ${ }^{101}$. A pesar de ello, el hecho de haber vivido en una época en la que la falta de recursos limitó el número y la ambición de las iniciativas constructivas y artísticas, unido a la desaparición o posterior remodelación de muchas de sus obras, con el añadido de las lagunas documentales que hemos podido constatar, han provocado que la figura de Sebastián de Vidal sea poco conocida.

Fecha de recepción: 29 de octubre de 2020.

Fecha de aceptación: 2 de mayo de 2021.

\section{BIBLIOGRAFÍA}

Aguilar Priego, Rafael (1954): "La Capilla Mayor del Convento de Santa Isabel de los Ángeles. Pedro Roldán. Discurso de recepción como Académico Numerario, 31 de enero de 1953”. En: Boletín de la Real Academia de Córdoba de Ciencias, Bellas Letras y Nobles Artes, 71, pp. 189-238.

Alonso Ruiz, Begoña (2012): "El maestro de obras catedralicio en Castilla a finales del siglo XV". En: Anales de Historia del Arte, 1, pp. 225-243.

Aranda Doncel, Juan (1984): Historia de Córdoba, vol. 3. La época moderna (1517- 1808). Córdoba: Monte de Piedad y Caja de Ahorros de Córdoba.

Aranda Doncel, Juan (2012): "Movimientos migratorios en las ciudades andaluzas: los portugueses en la Córdoba del siglo XVII”. En: Actas del I Congresso

99 Raya Raya, 1987b: 218.

100 Chueca Goitia, 1969.

101 Participó en la terminación del retablo mayor de la catedral y avisó de "la necescidad grande de rreparo que tiene la torre de esta santa Yglesia y ruyna que amenaza" que no se acometería hasta la segunda mitad del siglo. De la Torre y del Cerro, 1930: 305-306 y 317. 
Histórico Internacional. As cidades na História: População. Guimarães: Câmara Municipal de Guimarães, vol. 3, pp. 59-78.

Aroca Lara, Ángel (1986): "La escultura cordobesa del Seiscientos". En: Antonio del Castillo y su época. Córdoba: Diputación de Córdoba, pp. 149-197.

Blasco Esquivias, Beatriz (1991): "Sobre el debate entre arquitectos profesionales y arquitectos artistas en el barroco madrileño. Las posturas de Herrera Barnuevo, Herrera el Mozo, Olmo y Ardemans". En: Espacio, Tiempo, Forma, serie VII, n. ${ }^{\circ} 4,1991$, pp. 20-34.

Cerrato Mateos, Felisa (2006): El Císter de Córdoba. Historia de una clausura. Córdoba: Universidad de Córdoba.

Cruz Isidoro, Fernando (1993): "José García, maestro mayor del concejo Hispalense". En: Laboratorio de Arte, 6, pp. 103-127.

de la Torre y del Cerro, José (2012): El Inca Garcilaso de la Vega: (nueva documentación) estudio y documentos. Sevilla: Instituto Hispano-Cubano de Historia de América. (1930): "Obras en la torre de la Catedral de Córdoba en los siglos XVI y XVII". En: Boletín de la Real Academia de Ciencias, Bellas Artes y Nobles Artes de Córdoba, 29, pp. 297-323.

Chueca Goitia, Fernando (1969): "El protobarroco andaluz: Interpretación y síntesis”. En: Archivo Español de Arte, 166, pp. 139-153.

Díaz Rodríguez, Antonio José (2012): El clero catedralicio en la España moderna: los miembros del cabildo de la catedral de Córdoba (1475-1808). Murcia: Universidad de Murcia.

Falcón Márquez, Teodoro (2013): "El arquitecto de retablos y escultor Martín Moreno y los primeros retablos con columnas salomónicas en Sevilla”. En: Boletín de Arte, 34, pp. 70-87.

García Gómez, Ángel María (1990): Casa de las Comedias de Córdoba. 16021694: Reconstrucción documental. Madrid: Támesis.

(1999): Actividad teatral en Córdoba y arrendamiento de la casa de las comedias: 1602-1737. Estudio y documentos. Madrid: Támesis.

García Morales, María Victoria (1991): "El ejercicio como arquitectos de pintores y escultores en el siglo XVII". En: Velázquez y el arte de su tiempo. V Jornadas de Arte. Madrid: Editorial Alpuerto.

Gómez Bravo, Juan (1778): Catálogo de los Obispos de Córdoba y breve noticia histórica de su Iglesia Catedral y Obispado. Tomo II. Córdoba: en la oficina de D. Juan Rodríguez.

Japón Franco, Rafael (2013): "El expolio del arzobispo Luis Fernández de Córdoba en 1625: el retablo mayor de la parroquia de Guadalcázar y las pinturas del palacio arzobispal de Sevilla". En: Ucoarte. Revista de Teoría e Historia del Arte, 2, pp. 51-66.

Kubler, George (1957): Arquitectura de los siglos XVII y XVIII. Vol. 14 de Ars Hispaniae. Madrid: Plus-Ultra. 
Llaguno y Amírola, Eugenio/Ceán Bermúdez, Juan Agustín (1977): Noticias de los arquitectos y arquitectura de España desde su restauración. Madrid: Ediciones Turner, vol. 3. y vol. 4.

Luque Carrillo, Juan (2019): "Sobre el maestro de cantería Juan de Ochoa y sus trabajos para el II señor de Villaseca, don Luis Gómez de Figueroa y Córdoba". En: Ambitos: revista de estudios de ciencias sociales y humanidades, 41, pp. 25-33.

Martín González, Juan José (1984): El artista en la sociedad española del siglo XVII. Madrid: Cátedra.

Moreno Hurtado, Antonio (2020): "Las capillas barrocas de la Parroquia de la Asunción y Ángeles (III)”. En: http://www.laopiniondecabra.com/ampliar. php?sec $=$ especiales\&sub=colaboraciones\&art=1551 (27-3-2021).

Nieto Cumplido, Manuel (2007): La catedral de Córdoba. Córdoba: Cajasur.

Ortí Belmonte, Miguel Ángel (1980): Córdoba monumental, artística e histórica. Córdoba: Diputación de Córdoba.

Pita Andrade, José Manuel (1983): "La arquitectura española del siglo XVII". En: Hernández Díaz, José/Martín González, Juan José/Pita Andrade, José Manuel: La escultura y la arquitectura españolas del siglo XVII, Summa Artis, vol. 26. Madrid: Espasa Calpe, pp. 429-652.

Ramírez de las Casas Deza, Luis María [1862 (1923)]: "Noticia histórica de la Colegial de San Hipólito" [ed. de José Carlos de Luna]. En: Boletín de la Real Academia de Córdoba de Ciencias, Bellas Letras y Nobles Artes, 5.

Raya Raya, María Ángeles (1987a): El retablo barroco cordobés. Córdoba: Monte de Piedad y Caja de Ahorros. (1987b): "El retablo del siglo XVII en Córdoba". En: Imafronte, no 3-4-5, pp. 207-224. (2013): “Vidal, Sebastián”. En: Diccionario biográfico español. Madrid: Real Academia de la Historia. Tomo XLIX, pp. 888-889.

Romero de Torres, Enrique (1934): "Una obra desconocida del escultor Alonso de Mena, en el Retablo Mayor de la Catedral de Córdoba". En: Anuario del cuerpo facultativo de archiveros, bibliotecarios y arqueólogos, 1, pp. 293-298. (1936): "Nuevas noticias sobre la familia de los grandes escultores y arquitectos cordobeses, Felipe y Francisco Dionisio de Rivas, que florecieron en Sevilla en el siglo XVII: Aportaciones para la Historia del Arte en Córdoba”. En: Boletín de Belllas Artes, 3, pp. 34-54.

Sáenz de la Calzada Gorostiza, Consuelo (1956): "El retablo barroco español y su terminología artística. Sevilla". En: Archivo Español de Arte, 115, pp. 218-219.

Sainz y Gutiérrez, Luis (1894): "Datos históricos acerca de la construcción del puente llamado de Córdoba en la carretera de primer orden de Madrid a Cádiz". En: Revista de Obras Públicas. Anales, 3, pp. 5-129.

Valverde Madrid, José (1977): "Pedro Freila Guevara, un escultor barroco". En: Boletín de Bellas Artes de la Real Academia de Bellas Artes Santa Isabel de Hungría de Sevilla, 5, pp. 169-200.

Vigara Zafra, José Antonio (2011): Del gremio a la academia: El pintor Diego Monroy y la disolución del antiguo régimen artístico. Madrid: UNED. 


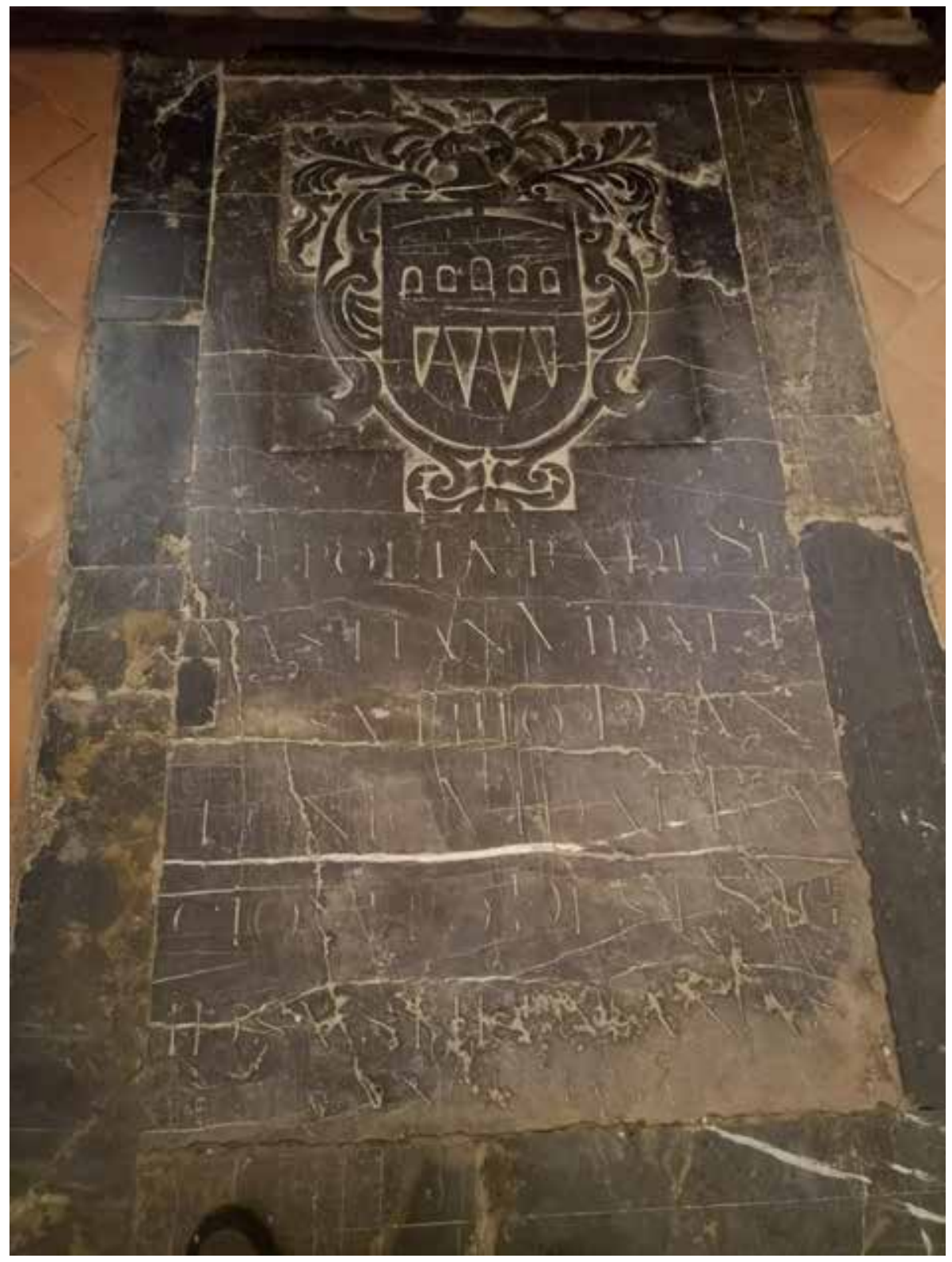

Figura 1. Lauda sepulcral de Sebastián Vidal, exteriores de la capilla de San Antonio 1676, catedral de Córdoba. Foto: Jesús Suárez Arévalo. 


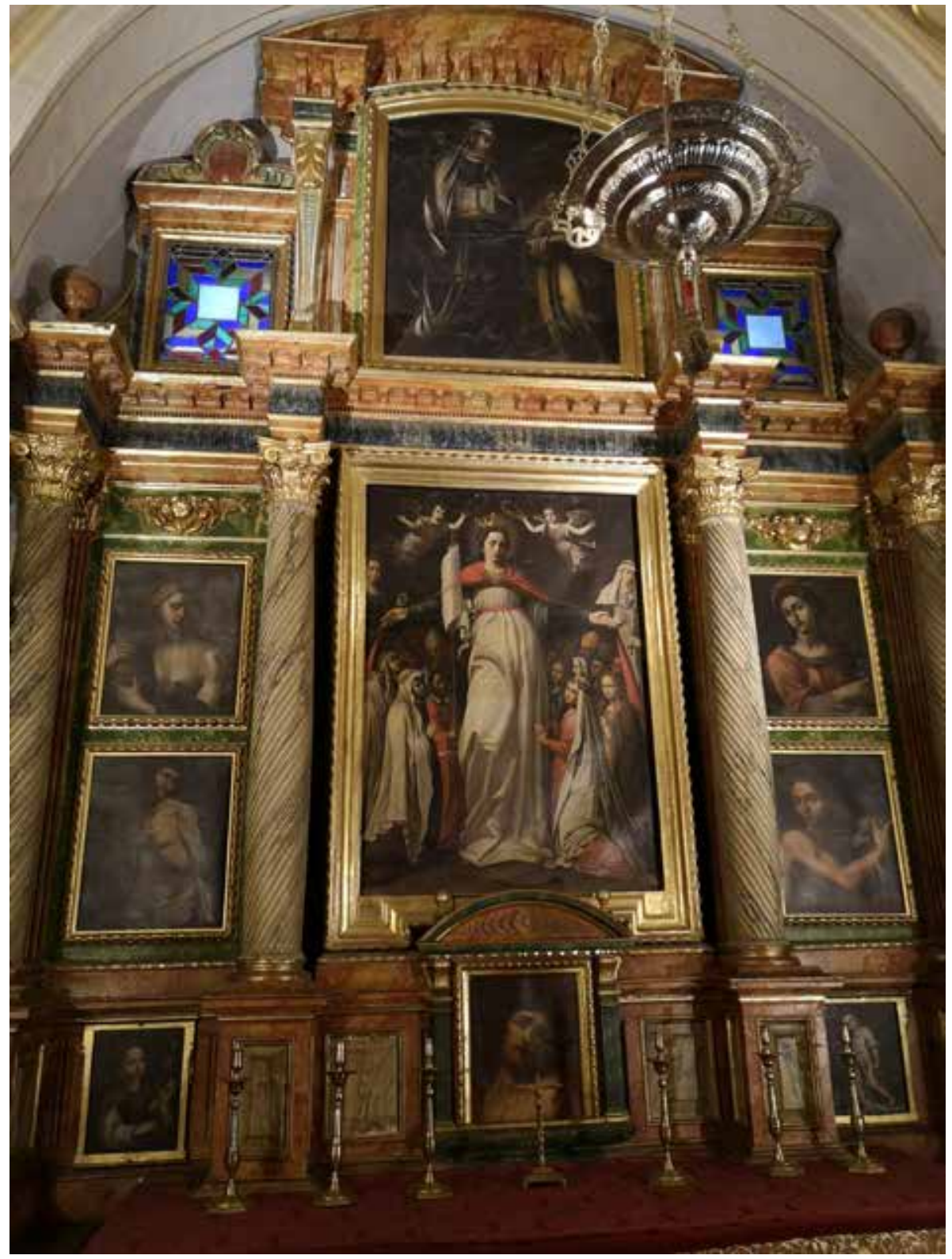

Figura 2. Sebastián Vidal, retablo de la capilla de santa Úrsula y santa Francisca Romana, 1627, catedral de Córdoba. Foto: Jesús Suárez Arévalo. 


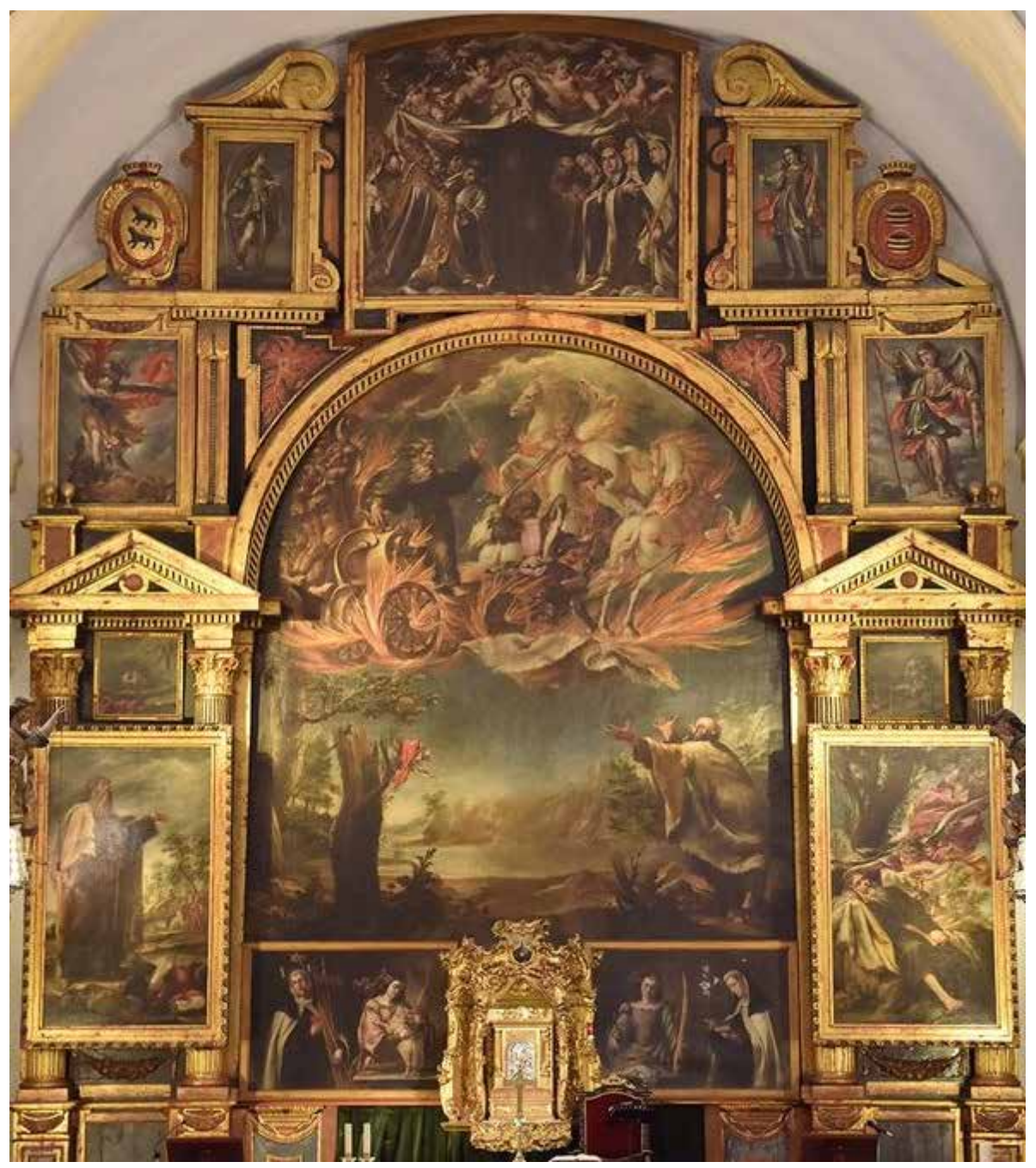

Figura 3. Sebastián Vidal (trazas), Pedro Freila (ejecución) y Juan de Valdés Leal (pinturas), 1639, retablo mayor de la iglesia de Ntra. Sra. del Carmen de Córdoba. Foto: Jesús Suárez Arévalo. 


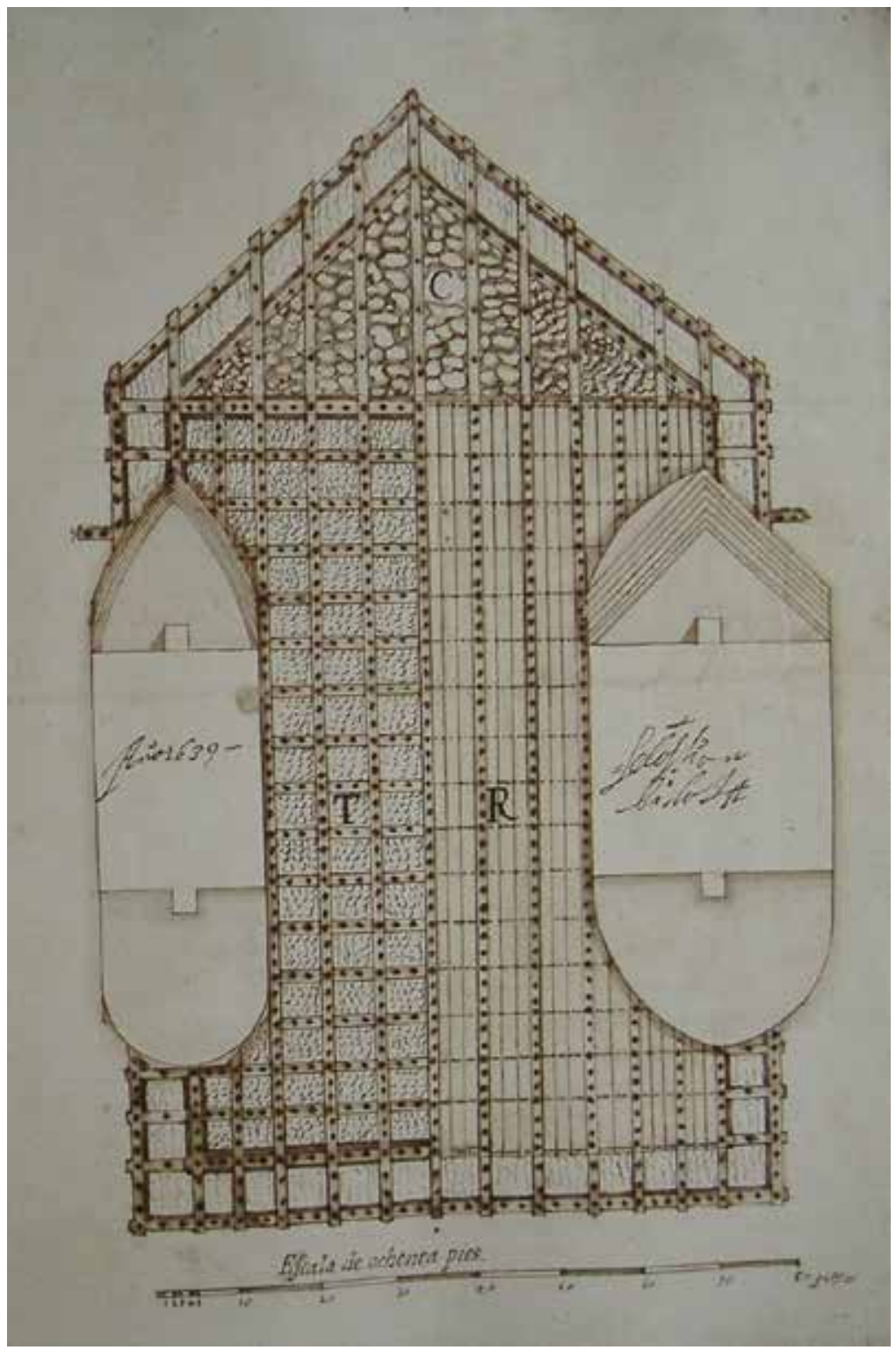

Figura 4. Sebastián Vidal, planta de los reparos del puente, 1639, Archivo municipal de Córdoba, SF-C-00108-070.

Foto: Archivo municipal de Córdoba. 


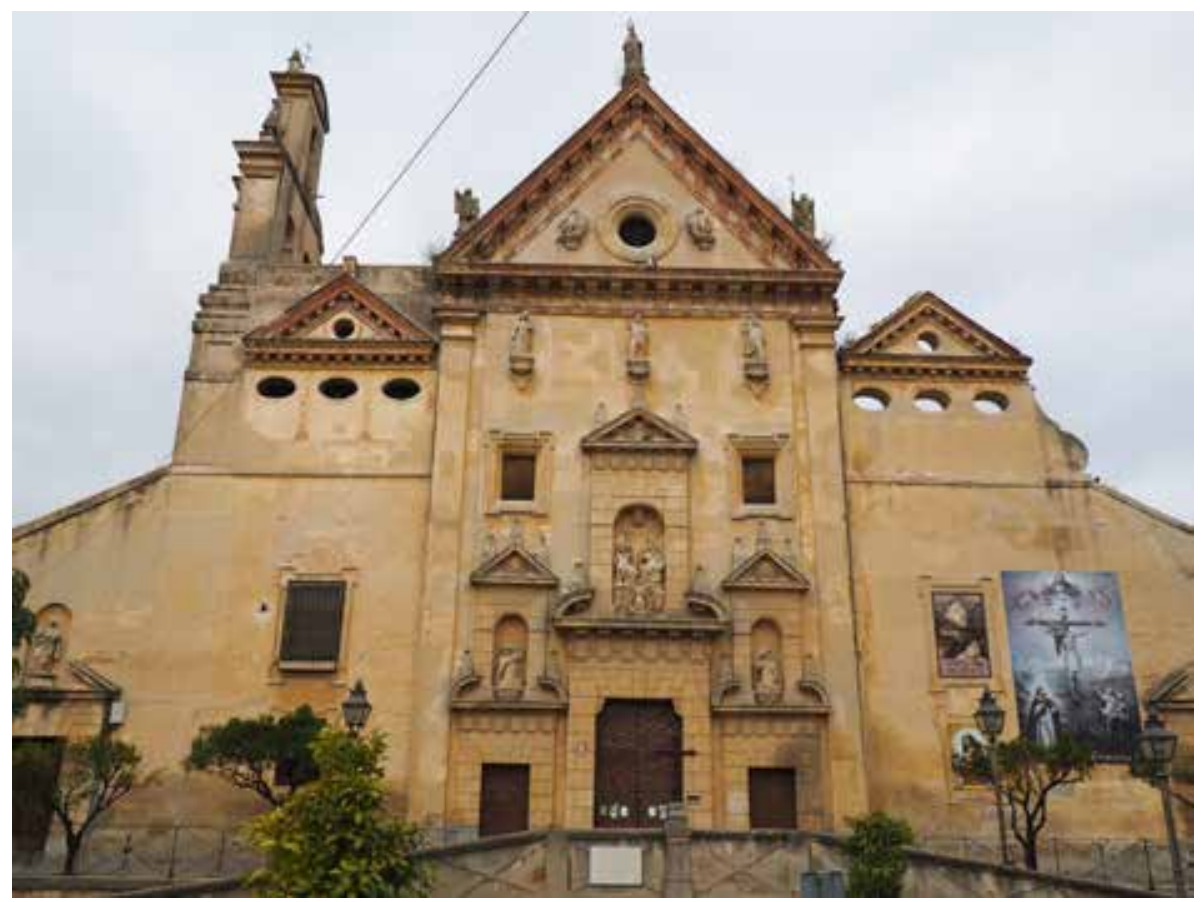

Figura 5. Sebastián Vidal (trazas), fachada de la iglesia de Nuestra Señora de Gracia (antiguo convento de los trinitarios), Córdoba. Foto: Jesús Suárez Arévalo. 